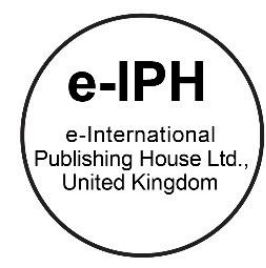

\title{
Factors for Effective Repair and Maintenance Services in the Housing Industry
}

\author{
Farhan Md Dahlan, Asniza Hamimi Abdul Tharim, Ashrof Zainuddin, Mohd Hasrol Haffiz Aliasak \\ Faculty of Architecture, Planning and Surveying, \\ Universiti Teknologi MARA Perak Branch, Seri Iskandar Campus, Seri Iskandar, 32610 Perak, Malaysia
}

farha221@uitm.edu.my, asnizahamimi7@gmail.com, ashro769@uitm.edu.my, hasrol170777@gmail.com

Tel: 017-5434356

\begin{abstract}
Most residents of high-rise housing do not realize the importance of proper building management until their physical buildings and shared facilities have deteriorated. This paper identifies the factors for effective repair and maintenance services in a housing setting. The study uses systematic literature review method analyzed through content analysis techniques with peer-reviewed journal articles. Results include potential factors for effective repair and maintenance services in high-rise housing. This study contributes by giving valuable reference to the property management companies managing such houses to consider the factors for effective repair and maintenance towards building quality and sustainability.
\end{abstract}

Keywords: Effective repair \& maintenance services; High-rise Housing; Housing Industry

eISSN: 2398-4287 @ 2019. The Authors. Published for AMER ABRA cE-Bs by e-International Publishing House, Ltd., UK. This is an open access article under the CC BYNC-ND license (http://creativecommons.org/licenses/by-nc-nd/4.0/). Peer-review under responsibility of AMER (Association of Malaysian Environment-Behaviour Researchers), ABRA (Association of Behavioural Researchers on Asians) and cE-Bs (Centre for Environment-Behaviour Studies), Faculty of Architecture, Planning \& Surveying, Universiti Teknologi MARA, Malaysia.

DOI: https://doi.org/10.21834/e-bpj.v4i12.1938

\subsection{Introduction}

The world is going through urban population growth, resulting in increasing population density. According to the United Nations (2018), the urban population of the world has proliferated since the 1950s from 751 million to 4.2 billion in $2018.82 \%$ of the North American population lives in urban areas in 2018, Latin America and the Caribbean reports $81 \%$ urban population, Europe $(74 \%)$ and Oceania $(68 \%)$. These are the most urbanized regions of the world. While in Asia, the level of urbanization is now approximating about $50 \%$ of the population. This phenomenon greatly affects the housing stock demand. Indeed with the scarcity of land areas, urban cities cannot expand horizontally anymore. Consequently, the government decides on high-rise strata housing as a possible solution to cater to the increasing population growth and development density in the urban areas (Verhaeghe, Coenen, and Putte, 2016).

Unlike the free-standing house, these types of living areas come complete with facilities and amenities at the common areas (Musa, Sarip, Aziz, Hanif, Al-Sadat, and Tedong, 2015) such as parking areas, lighting, lifts, swimming pool, gym and other common facilities provided by the developer. With adequate management and maintenance, those facilities and amenities create and sustain a healthy living environment (Sia, Yew, Lim, and Dongqing, 2017). However, these types of housing are less satisfactory than other housing forms (Gifford, 2011) as they pose higher risks in older aged buildings than large, modern buildings. These risks may result in catastrophic consequences if building failures occur (Yau, $\mathrm{Ho}$, and Chau, 2008). Ignorance in taking care of such buildings may lead to high levels of housing deterioration (Ganisen, Nesan, Mohammad, Mohammed, and Kanniyapan, 2015; Vergara, Gruis, and Flier, 2019). All these undoubtedly render an increase in maintenance activities and result in unreliable operation costs (Ganisen et al., 2015; Mohamed Isa and Usmen, 2015).

This type of housing relies on the type of residential management (e.g., management body or the property management companies) as poor management execution can negatively impact upon quality governance, which affects the way they manage and maintain the

eISSN: 2398-4287 @ 2019. The Authors. Published for AMER ABRA cE-Bs by e-International Publishing House, Ltd., UK. This is an open access article under the CC BYNC-ND license (http://creativecommons.org/licenses/by-nc-nd/4.0). Peer-review under responsibility of AMER (Association of Malaysian Environment-Behaviour Researchers), ABRA (Association of Behavioural Researchers on Asians) and cE-Bs (Centre for Environment-Behaviour Studies), Faculty of Architecture, Planning \& Surveying, Universiti Teknologi MARA, Malaysia. DOI: https://doi.org/10.21834/e-bpj.v4i12.1938 
building. Controlling the root cause of maintainability risks preserves the structure physically and ensures the facilities' performance (Silva and Ranasinghe, 2010). A capable management team is crucial to guarantee appropriate management and maintenance of the building. Previous findings by scholars report that the organizations that properly manage the buildings have positive correlations with the building performance (Au-Yong, Shah Ali, Ahmad, and Chua, 2017). Qualitative findings by Levy and Sim (2014) iterate that the practices of a management body in managing the buildings influence the satisfaction level of the residents. In the same vein, earlier research by Christudason, (2008) finds the choice of a veritable residential management housing involves making discreet inquiries on its track records as they will impact the performance of the building. In concurrence, current research using quantitative methods and interviews with experts prove that actively collecting and timeously responding to new information such as residents' complaints or facility failures on an ongoing basis, and progressing on effective repair and maintenance of the management (Shin, Soo Lee, Park, and Lee, 2018) all contribute towards building performance.

In western countries such as New Zealand, Levy and Sim (2014) report that the residents replace the management due to them experiencing dissatisfaction and frustration of the current management's performance. In the United Kingdom, Tucker, Turley and Holgate (2014) identify the critical factors towards cost-effectiveness in dealing with the uncertain financial conditions in social housing maintenance management. Meanwhile, in Australia, Johnston and Too (2015) uphold that poor execution of the management systems results in negative quality governance. Negative quality governance leads to committee and management issues, meetings issues, transparency and accountability issues, business activity issues, financial management issues, administration issues, by-laws issues, and asset and shared property issues. In Asian countries, there are prevalent records in previous studies that practices such as dealing with collective action problems (Chu, Chang, and Sing, 2013; Ho and Gao, 2013), free-riders (Christudason, 2004; Yau, 2018), and power monopoly (Lam, 2008) link with an ineffective maintenance management problems.

Similarly, in Malaysia, ineffective maintenance management is a critical issue in dealing with high-rise strata housing. In line with the trend of high-rise housing, this study is imperative to safeguard the implications of high-rise strata housing growth. There is an abundance of studies on factors for effective repair and maintenance services in non-residential buildings, but there is a lack of reviewed studies in a housing setting. Therefore, this paper aims to identify factors for effective repair and maintenance services in a housing setting.

\subsection{Methodology}

A systematic review is an examination of a formulated question that uses systematic and explicit methods to identify, select and critically appraise relevant research, and to collect and analyze data from studies in the review. The conduct of this systematic review is in line with the Preferred Reporting Items for Systematic Reviews Statistical and Meta-Analyses (PRISMA) Standard (Moher, Liberati, Tetzlaff, and Altman, 2009) which involves the identification of literature, eligibility and exclusion criteria, data abstraction and lastly analysis.

\subsection{Identification of Literature}

Identification of literature was via queries into the databases of peer-reviewed sources; Web of Science (WoS) and Scopus. The selection of the publication on those two databases covers more than 20,000 journals which consist of over 256 disciplines. The queries during this phase use keywords as per Table 1. The search results in 95 articles. Table 1 summarizes the search string.

Table 1: The search string for the systematic review process

\begin{tabular}{ll} 
Table 1: The search string for the systematic review process \\
\hline Databases & Keywords used \\
\hline Scopus & TITLE-ABS-KEY (("Efficient maintenance management" OR "effective \\
& maintenance management" OR "maintenance management" AND \\
& "hous*") AND ( LIMIT-TO ( DOCTYPE, "ar" ) ) AND ( LIMIT-TO ( \\
& LANGUAGE, \\
TS = ("Efficient maintenance management" OR "effective maintenance \\
management" OR "maintenance management" AND "hous")
\end{tabular}

Identification of additional records is by examining the reference lists of articles recovered through the databases search to capture any relevant studies missing when using the search strategy in the menu above.

\subsection{Eligibility and exclusion criteria}

At this stage, from 95 items identified earlier, the authors remove eight duplicate materials. Screening of the identified literature is according to several eligibility and exclusion criteria. First, with regards to literature type, the authors only select journal articles with empirical data. The selection of journal articles with empirical data only excludes review articles, conference proceedings, books, book series, and chapters in books. Secondly, the authors only consider peer-reviewed articles in the English language from scholarly journals to avoid any confusion and difficulties during the translation process. Thirdly, in terms of timeline, the authors decide on a period of the last ten years (from 2009 to 2019), which is an adequate period to see the evolution of research and related publications. Lastly, in line with the study objectives that focus on factors for effective repair and maintenance services, the authors only select articles focusing on building maintenance (see Table 2). 
Table 2. The Inclusion and Exclusion Criteria

\begin{tabular}{|c|c|c|}
\hline Criterion & Eligibility & Exclusion \\
\hline Literature type & Journal (research articles) & $\begin{array}{l}\text { Review articles, Conference proceedings, } \\
\text { book, book series, chapter in the book }\end{array}$ \\
\hline Language & English & Non-English \\
\hline Timeline & Between 2009 to November 2019 & $<2009$ \\
\hline
\end{tabular}

The process results in the exclusion of a total of 59 journal articles and the selection of the remaining 21 items for final eligibility before further analysis (see Fig. 1).

\subsection{Data abstraction and analysis}

Assessment and analysis of the remaining articles are by reading through the abstracts. Subsequently, an examination of the full-text articles identifies the themes and sub-themes according to the objectives of this paper. Establishment of themes and sub-themes uses content analysis of data related to effective repair and maintenance in the housing industry context.

\subsection{Result}

The review results in six themes and 12 sub-themes concerning factors of effective repair and maintenance services. The six main themes are residents' expectation (1 sub-theme), staff competence ( 2 sub-themes), learning and growth (2 sub-themes), financial ( 2 sub-themes), physical building conditions (3 sub-themes), and strategic management (2 sub-themes). The results provide a comprehensive analysis of the current factors of effective repair and maintenance services. A majority of the studies employs quantitative approaches. In contrast, others use qualitative and mixed-method ranges from experiences in Malaysia, Saudi Arabia, Nigeria, Taiwan, China, Hong Kong, United Kingdom, Chile, United States, and Australia.

\subsection{Findings}

This section concentrates on the main factors of effective repair and maintenance in the housing industry, such as residents' expectation, staff competence, learning and growth, physical building conditions, and strategic management.

\subsection{Residents' Expectation}

The residents' expectation requires organizations to consider their needs. The organizations should also set that the organization performance is neither under nor over performing. Nine articles identified study this factor for gaining effective repair and maintenance service (Tan, Shen, Langston, Lu, and Yam, 2014; Tucker, Turley, and Holgate, 2014; Wang, Chang, Zhang, Qin, and Jiang, 2015; Ganisen, Mohammed, Nesan, and Kanniyapan, 2015; Mukhtar, Amirudin, Sofield, and Mohamad, 2017; Au-Yong, Azmi, and Mahassan, 2018; Au-Yong, Ali, and Chua, 2019; Sivanathan, Juhari, Khair, Thanaraju, Azmi and Khan, 2019, and Vergara, Gruis, and Flier, 2019). Residents' expectation represents a significant factor for efficient repair and maintenance services for the organization to provide quality goods and services, effective delivery, and overall residents' satisfaction (Amaratunga and Baldry, 2003).

\subsection{Staff Competence}

The competence of staff is specific knowledge, motivation, skills, or social characteristics and roles per the demands of an organization. A total of three articles report that the competence of staff is one of the factors for effective repair and maintenance in housing buildings. Under this theme, two sub-themes emerge, namely skilled personnel and experienced personnel.

Wang, Chang, Zhang, Qin, and Jiang (2014) find that staff competence promotes professional levels of service and improves the quality of repair and maintenance operations in Taiwan and China. Therefore, a personnel qualification certification system is necessary for any individual aspiring to join the repair and maintenance operations. In Hong Kong, company certification practice reflects the reputation of the company, meaning they employ qualified staff (Tan, Shen, Langston, Lu, and Yam, 2014). They believe that skilled and experienced personnel could provide quality service delivery in terms of repair and maintenance service activities. A study by Akinsola, Hussaini, Oyenuga, and Fatokun (2012) focus on adequate and skilful personnel to avoid job delays, which means the maintenance team promptly responds to complaints received.

\subsection{Learning and Growth}

The learning and growth factor is how well the organization learns and improves its performance continuously. Scrutiny on a total of three studies highlighting this element establishes two sub-themes, which are adapting to changes and technology advancement. According to the articles, the ability of the employees needs to adapt to changes (Perkins, Grey and Remmers, 2014) and technology advancement (Lin and Su, 2013; Assaf, Al-Hammad, and Al-Shihah, 2010) is vital for alignment of the organizational goals. Hence, organizations focusing on effective repair and maintenance must create long-term growth and improve continuously. 


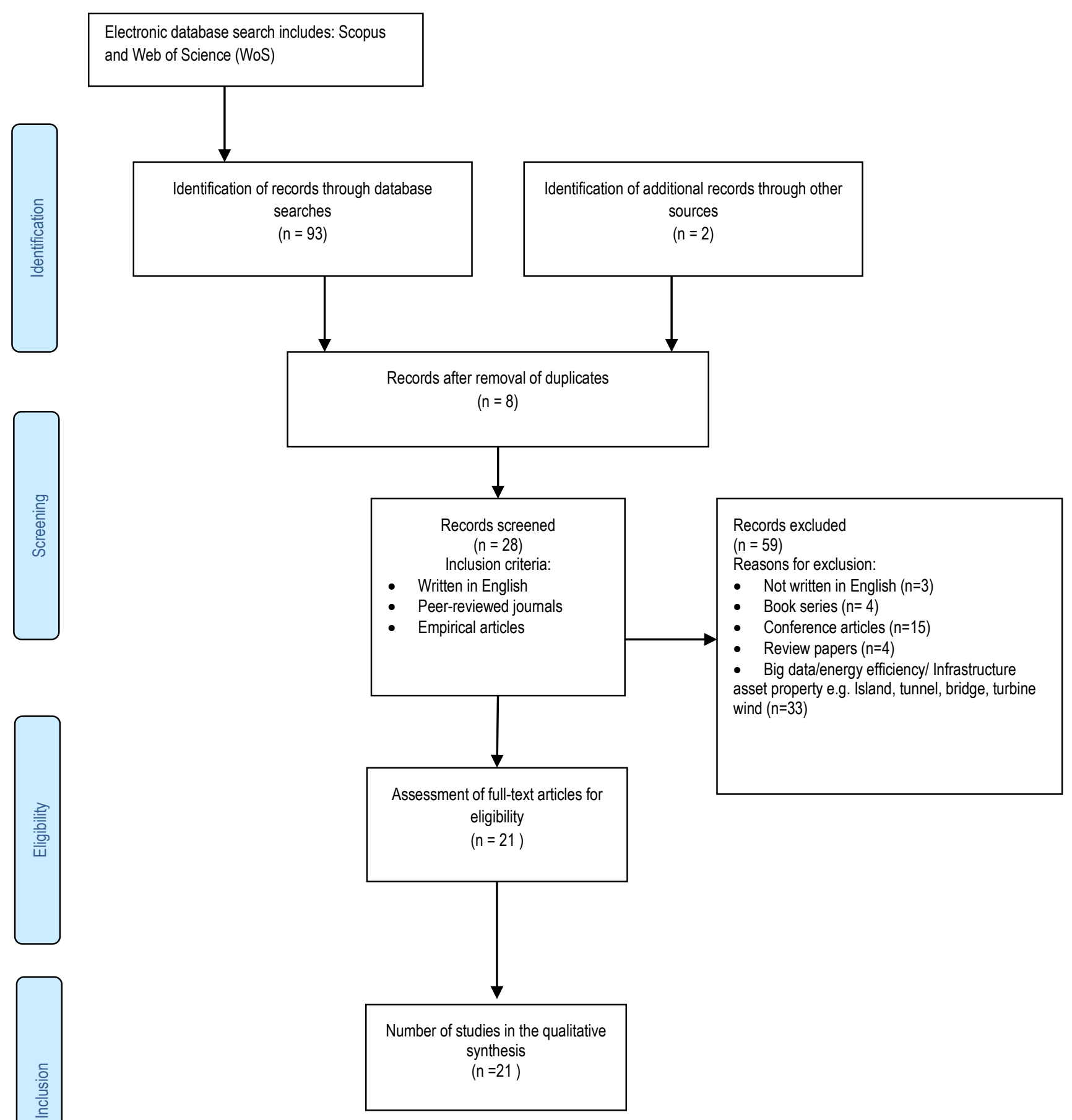

Fig. 1: The flow diagram of the research. (Adaptation from Moher et al., 2009)

\subsection{Financial}

Financial factors are essential to the survival of managing and running repair and maintenance activities towards sustaining building life. Three studies find emphasis on budget allocation (Syah Ali, Kamaruzzaman, Sulaiman, and Au-Yong, 2010; Akinsola et al., 2012; AuYong, Jin, et al., 2019), and collection of fund from residents (Syah Ali, Kamaruzzaman, Sulaiman, and Au-Yong, 2010; Wang et al., 2015; Vergara, Gruis, and Flier, 2019).

In high-rise strata housing, loan facilities are essential to pay the management fund for administration and utilities, maintenance fund for exclusive facilities, maintenance fund for necessary facilities, maintenance fund for support facilities, and management sinking fund (Abd Wahab, Che Ani, Sairi, Mohd Tawil, and Abd Razak, 2016). Financial management plays a crucial role in the housing industry as 
various management tasks, particularly the maintenance activities, are only possible with sufficient financial resources. Therefore, the management should creatively manage the defaulters to minimize arrears occurring.

\subsection{Strategic Management}

Strategic management is the organization's management resource to achieve its goals. Three studies out of 17 articles report that quality improvement and response time are the critical factors for effective repair and maintenance services. Assaf et al., (2010), Tucker, Turley, and Holgate (2014), and Vergara et al., (2019) highlight that quality improvement is a necessity in maintaining their business and building trust among the management body and residents. Besides, response time towards complaints impact the satisfaction of residents (Akinsola et al., 2012; Tan et al., 2014; Vergara et al., 2019). The faster the response, the higher the residents' satisfaction.

\subsection{Physical Building Condition}

Almost half of the identified articles focus on physical building condition. The findings show that this factor is the most critical among all the factors as the frequency is the highest. Data analysis establishes three sub-themes, which is firstly building materials (Syah Ali et al., 2010). The second sub-theme is building age (Syah Ali et al., 2010), and the third sub-theme is building design (De Silva et al., 2012; Ganisen, Mohammed, Nesan and Kanniyapan, 2015; Sajan, 2015; Adewunmi, Omirin, and Koleoso, 2016; Mukhtar, Amirudin, Sofield, and Mohamad, 2017; Vergara et al., 2019; Fatayer, Hassanain, Abdallah, and Al-Hammad, 2019).

A total of six articles emphasize the design adequacies that affect the effectiveness of repair and maintenance activities during the post-occupancy period. Additionally, Syah Ali et al. (2010) reiterate that quality materials and specification compliance influence the effectiveness of the maintenance works. Finally, the third sub-theme (building age) from later researchers found that the age of a building may impact the effectiveness of the repair and maintenance works.

\subsection{Discussion}

This study attempts to systematically analyze the existing studies on factors of effective repair and maintenance services in the housing industry. Preserving the physical building condition could maintain the sustainability and the lifespan of the housing. An increase in the high-rise strata housing stocks in current years is a vital signal for the government as well as the developers to highlight the issue.

The review sourced from two databases reveals 21 articles on factors of effective repair and maintenance service in the housing industry. Within the scope of the evaluation, six themes and 11 sub-themes emerge, which are residents' expectation, the competence of staff, learning and growth, financial, strategic management, and physical building conditions.

More than half of the identified articles concentrate on building design. It shows that managing repair and maintenance management in the housing setting is a complex issue as it involves pre and post-construction stakeholders' involvement from the early stage of design until the end of the building life. The root maintenance risk should be taken into consideration from the schematic design stage by the design team and also the developer of the development. They need to keep minding their design could minimize the operation maintenance cost for the whole life cycle of the building. During this period, the involvement of facilities managers' experience and knowledge is pivotal. Furthermore, the property management performance and work culture need to implement practices such as dealing with human behavior, debt collection, and prioritization of the maintenance activities.

\subsection{Conclusion and Recommendations}

The results indicate six significant potential factor variables (i.e., residents' expectation, staff competence, learning and growth, financial, physical building conditions, and strategic management) for effective repair and maintenance services in the housing setting. In sum, our findings are one of the first attempts towards building a complete theory in maintenance housing setting and has significant implications for effective repair and maintenance management in general. The study is, of course, not exempt from limitations. The reader should give caution to the generalization of our results to a property management company. The authors believe, however, that the factors are neither feasible nor necessary. Future work may integrate more than ten years' range of review to identify more factors of effective repair and maintenance services in the housing industry. This is a conceptual study. Empirical work is therefore, necessary to refine and validate the factors.

\section{Acknowledgements}

The authors wish to express their gratitude towards Universiti Teknologi MARA, Perak Branch, Seri Iskandar Campus for the support in the form of a grant [900-KPK/PJ//GKIPP/01(0013/2018)] which made this paper possible. The authors also wish to acknowledge the two anonymous referees and the managing editor of this conference for their constructive comments, which have greatly improved the paper. 
Md Dahlan, F., et.al. / $8^{\text {th }}$ AcE-Bs2019Langkawilsland, Malaysia 18-19 Dec 2019 /E-BPJ, 4(12), Dec. 2019 (pp.241-248)

Table 3: The findings

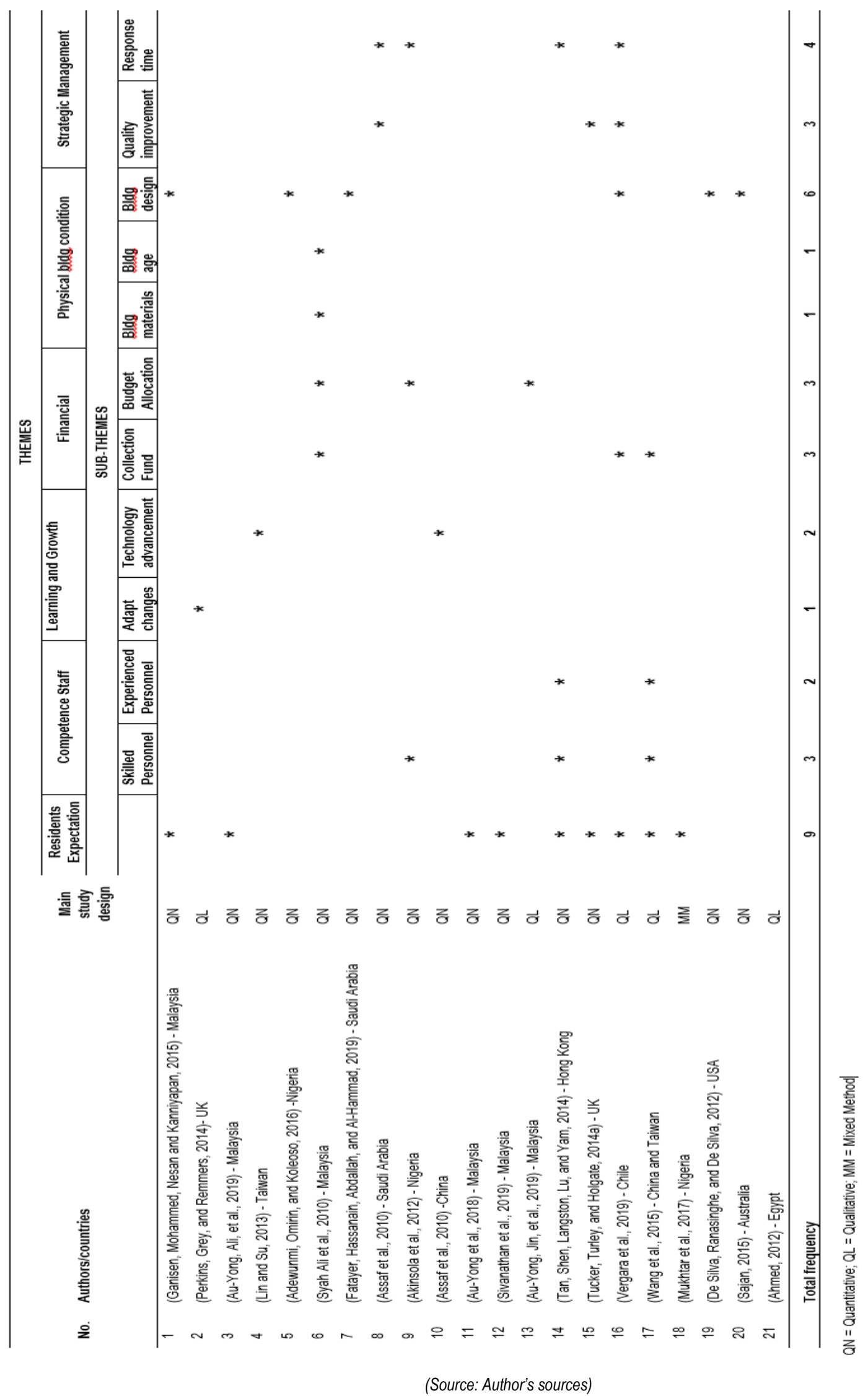




\section{References}

Abd Wahab, S. R. H., Che Ani, A. I., Sairi, A., Mohd Tawil, N., \& Abd Razak, M. Z. (2016). A Survey on Classification of Maintenance Fund For High Rise Residential Building in Klang Valley. Proceedings of the International Conference on Applied Science and Technology 2016 (ICAST'16), 1-6.

Adewunmi, Y., Omirin, M., \& Koleoso, H. (2016). Prioritising facilities management services for benchmarking in selected cities in Nigeria. Journal of Construction in Developing Countries, 21(1), 131-145.

Ahmed, K. G. (2012). Residents' socio-cultural dissatisfaction in the two stages of public housing in Cairo, Egypt: What has changed in the third "current" one? Urban Design International, 17(3), 159-177.

Akinsola, O. E., Hussaini, P. O., Oyenuga, S. O., \& Fatokun, A. O. (2012). Critical factors influencing facility maintenance management of tertiary institutional buildings in Southwest Nigeria. Mediterranean Journal of Social Sciences, 3(11), 489-496. https://doi.org/10.5901/mjss.2012.v3n11p489

Amaratunga, D., \& Baldry, D. (2003). A conceptual framework to measure facilities management performance. Property Management, 21(2), 171-189.

Assaf, S., Al-Hammad, A., \& Al-Shihah, M. (1995). The effect of faulty construction on building maintenance. Building Research \& Information, $23,175-181$.

Au-Yong, Azmi, N. F., \& Mahassan, N. A. (2018). Maintenance of lifts systems affecting resident satisfaction in low-cost high-rise residential building. Journal of Facilities Management, 16(1), 17-25.

Au-Yong, C. P., Ali, A. S., \& Chua, S. J. L. (2019). Maintenance priority in high-rise housings: Practitioners' perspective versus actual practice. Journal of Engineering Research (Kuwait), 7(2), 167-177.

Au-Yong, C. P., Jin, S., Chua, L., Ali, A. S., Tucker, M., Au-yong, C. P., ... Ali, A. S. (2019). Optimising maintenance cost by prioritising maintenance of facilities services in residential buildings. Engineering, Construction and Architectural Management, 26(8), 1593-1607. https://doi.org/10.1108/ECAM-07-2018-0265

Christudason, A. (2004). Common property in strata titled developments in Singapore: common misconceptions. Property Management, 22(1), 14-28.

Chu, F., Chang, C., \& Sing, T. F. (2013). Collective action dilemmas in condominium management. Urban Studies, 50(1), 128-147.

De Silva, N., Ranasinghe, M., \& De Silva, C. R. (2012). Risk factors affecting building maintenance under tropical conditions. Journal of Financial Management of Property and Construction, 17(3), 235-252.

Fatayer, F. A., Hassanain, M. A., Abdallah, A., \& Al-Hammad, A.-M. (2019). Investigation of facilities management practices for providing feedback during the design development and review stages. International Journal of Building Pathology and Adaptation, 37(5), 597-614.

Ganisen, S., Mohammed, A. H., Nesan, L. J., \& Kanniyapan, G. (2015). Critical success factors for low cost housing building maintenance. Jurnal Teknologi, 2(2015), $31-40$.

Gifford, R. (2011). The Consequences of Living in High-Rise Buildings. Architectural Science Review, 50.1, 2-17.

Ho, D. C. W., \& Gao, W. (2013). Collective action in apartment building management in Hong Kong. Habitat International, 38(1), $10-17$.

Johnston, N., \& Too, E. (2015). Multi-owned properties in Australia: a governance typology of issues and outcomes. International Journal of Housing Markets and Analysis, $8(4), 451-470$.

Levy, D., \& Sim, Q.H. (2014). Why multi-owned housing owners are dissatisfied with the service provided by their management companies in New Zealand. International Journal of Housing Markets and Analysis, 7(3), 397-416.

Lin, Y. C., \& Su, Y. C. (2013). Developing mobile- and BIM-based integrated visual facility maintenance management system. The Scientific World Journal, $2013,1-10$. https://doi.org/10.1155/2013/124249.

Moher, D., Liberati, A., Tetzlaff, J., \& Altman, D. G. (2009). Preferred reporting items for systematic reviews and meta-analyses: The PRISMA statement. BMJ (Online), 339(7716), 332-336. https://doi.org/10.1136/bmj.b2535.

Mukhtar, M. M., Amirudin, R., Sofield, T., \& Mohamad, I. (2017). Critical success factors for public housing projects in developing countries: A case study of Nigeria. Environment, Development and Sustainability, 19(5), 2039-2067.

Musa, Z., Sarip, A., Aziz, W., Hanif, N., Al-Sadat, Z., \& Tedong, P. (2015). Issues in managing vertical residential building in Malaysia: Homeowners perspective. The Asia Pasific Networkfor Housing Research (APNHR), 1-8. Gwangju, Korea: Korean Housing Association and Korea Land and Housing Corporation.

Perkins, M., Grey, A., \& Remmers, H. (2014). What do we really mean by "Balanced Scorecard"? International Journal of Productivity and Performance Management, 63(2), 148-169.

Sajan, J. (2015). Design implications for multi-owned properties from a household survey. International Journal of Housing Markets and Analysis, 8(7), 502-518.

Shin, H., Soo Lee, H., Park, M., \& Lee, J. G. (2018). Facility Management Process of an Office Building. Journal of Infrastructure Systems, 24(3), 1-11.

Sia, M. K., Yew, V. W. C., Lim, Z. Y., \& Dongqing, Y. (2017). Facilities and maintenance services for sustainable high-rise living. Facilities, 36(7/8), 330-348.

Silva, N. De, \& Ranasinghe, M. (2010). Maintainability risks of condominiums in Sri Lanka. Journal of Financial Management of Property and Construction, 15(1), 41-60.

Sivanathan, S., Juhari, N. H., Khair, N., Thanaraju, P., Azmi, A., \& Khan, P. A. M. (2019). Assessment of residents' satisfaction on building maintenance in public lowcost housing. International Journal of Recent Technology and Engineering, 8(1), 260-265. 
Syah Ali, A., Kamaruzzaman, S. N., Sulaiman, R., \& Au-Yong, C. P. (2010). Factors affecting housing maintenance cost in Malaysia. Journal of Facilities Management, 8(4), 285-298. https://doi.org/10.1108/14725961011078990.

Tan, Y., Shen, L., Langston, C., Lu, W., \& Yam, M. C. H. (2014). Critical success factors for building maintenance business: A Hong Kong case study. Facilities, 32(5).

Tucker, M, Turley, M., \& Holgate, S. (2014). Critical success factors of an effective repairs and maintenance service for social housing in the UK. Facilities, 32(5), 226240.

United Nations. (2018). World Urbanization Prospects: The 2018 Revision-Key facts. https://doi.org/https://population.un.org/wup/Publications/Files/WUP2018KeyFacts.pdf.

Vergara, L. M., Gruis, V., \& Flier, K. van der. (2019). Understanding housing management by low-income homeowners: technical, organizational and sociocultural challenges in Chilean condominium housing. Buildings, 65(9), 1-21.

Verhaeghe, P., Coenen, A., \& Putte, B. Van De. (2016). Is Living in a High-Rise Building Bad for Your Self-Rated Health? Journal of Urban Health: Bulletin of the New York Academy of Medicine, 93(5), 884-898.

Wang, N., Chang, Y., Zhang, C., Qin, H., \& Jiang, D. (2014). Comparison of Housing Facility Management between Mainland China and Taiwan Region. Journal Performance Construction Facilities, 29(8), 1-5.

Yau, Y. (2018). Efficacy Beliefs and Homeowner Participation. In Erika Altmann \& Michelle Gabriel (Eds.), Multi-Owned Property in the Asia-Pacific Region (1st Eds.)(pp. 2-17). UK: Palgrave Macmillan UK.

Yau, Y., Ho, D. C. W., \& Chau, K. W. (2008). Determinants of the safety performance of private multi-storey residential Buildings in Hong Kong. Social Indicators Research, 89(3), 501-521. 